\title{
O COMBATE AO CRIME DE LAVAGEM DE DINHEIRO NO DIREITO INTERNO E INTERNACIONAL
}

\section{COMBATING THE CRIME OF MONEY LAUNDERING IN INTERNAL AND INTERNATIONAL LAW}

\section{ANDRÉA FLORES}

Doutora e Mestre em Direito pela PUC/SP, Advogada, Professora da Universidade Federal de Mato Grosso do Sul - UFMS, da Universidade Católica Dom Bosco UCDB e da Escola Superior da Magistratura de Mato Grosso do Sul - ESMAGIS.

\section{RODRIGO ALENCAR MACHADO CAMAPUM}

Delegado de Polícia Civil do Estado de Mato Grosso do Sul.

\section{RESUMO}

Este artigo tem por finalidade analisar os fenômenos que levaram o crime de lavagem de dinheiro a se expandir para jurisdições de diversos Estados. Tratando da origem do combate à lavagem de capitais, desde as medidas meramente administrativas, passando pela criminalização e evolução da legislação de combate até o presente momento. É analisado no presente trabalho a legislação interna, evolução e inovações legislativas, bem como os tratados internacionais que influenciaram a legislação brasileira.

PALAVRAS-CHAVE: Globalização; Lavagem de Dinheiro; Convenções Internacionais. 


\section{ABSTRACT}

This article aims to analyze the phenomena that led to the crime of money laundering to expand to the jurisdictions of several states. Addressing the origin of the fight against money laundering, from purely administrative measures, to the criminalization and evolution of legislation to date. Internal legislation, evolution and legislative innovations, as well as the international treaties that have influenced the Brazilian legislation, are analyzed in the present work.

KEYWORDS: Globalization; Money laundry; International Conventions.

\section{INTRODUÇÃO}

O presente artigo tem como finalidade analisar o fenômeno da globalização e suas implicações no comportamento social, bem como na criminalidade, estudando a influência da evolução tecnológica no que tange à sofisticação da criminalidade, tratando mais especificamente no crime de lavagem de capitais.

A abordagem parte do princípio de que o comportamento social vive em constante mudança, devendo o Direito Penal, bem como todo aparato de persecução penal de que dispõem os Estados, se aperfeiçoarem, a fim de garantir a efetividade das normas.

Será feita uma abordagem da legislação de combate à lavagem de capitais no Brasil e as influências que os tratados internacionais tiverem em sua construção até o presente momento.

Aborda-se a importância da ONU no combate à lavagem de dinheiro, bem como alguns tratados internacionais estabelecidos por tal organização, quais sejam, a Convenção de Viena de 1988, a Convenção de Palermo e a Convenção de Mérida.

Vale ressaltar que a ordem econômico-financeira protegida pela incriminação da lavagem de capitais visa, em segundo plano, proteger o desenvolvimento econômico do Estado e da sociedade, garantindo ao final a dignidade da pessoa humana. 
Assim, podemos concluir que a proteção promovida pelo combate à lavagem de capitais, por relacionar-se ao desenvolvimento, insere-se nos direitos humanos econômicos.

Como leciona Vladmir Oliveira da Silveira, a evolução histórica dos direitos humanos ocorre através da chamada dinamogênesis, mecanismo pelo qual a sociedade verifica uma alteração de comportamento, reconhecendo ser necessária a garantia de determinado valor que fundamenta o direito humano. A partir desse reconhecimento, passa a haver a normatização pelos Estados como ideia indispensável à dignidade da pessoa humana (SILVEIRA; CONTIPELLI, 2008).

Os direitos de cunho econômico estão incluídos nos direitos humanos de segunda geração, os quais demonstram um caráter prestacional, exigindo do Estado uma atuação voltada a atender as condições mínimas de dignidade da vida humana.

Como estudaremos, a globalização trouxe essa mudança de comportamento, definindo novos valores a serem tutelados, motivando o estabelecimento de normas internas e celebração de pactos internacionais, os quais visam garantir o desenvolvimento econômico e social dos Estados.

\section{GLOBALIZAÇÃO}

O processo de globalização, apesar de sua intensificação ocorrer há poucas décadas, pode ser verificado já nos séculos $X V$ e $X V I$, resultante dos aperfeiçoamentos das técnicas de navegação, onde os impérios se deslocavam pelos oceanos para realizarem comércios com outros Estados.

Ocorre que nos anos 80, com o avanço tecnológico foi possível atenuar as fronteiras que separavam os mercados financeiros dos Estados, possibilitando assim uma maior interação entre os mesmos, desta maneira, por se tratar de uma ciência social, o direito está em constante alteração, devendo sempre acompanhar as transformações de comportamentos sociais e antissociais.

É possível verificar que a criminalidade toma novas formas com as mudanças dos comportamentos sociais. Assim, a ciência jurídica deve também se adaptar à nova 
realidade, trazendo novos conceitos e instrumentos para coibir a criminalidade que se transforma.

Trazemos a lume o conceito de Luiz Gonzaga da Silva Adolfo (2001, p.54), ipsi literis:

\begin{abstract}
Globalização refere-se a processos atuantes em escala global, que ultrapassam fronteiras nacionais, integrando e conectando comunidades e organizações em novas combinações de espaço-tempo tornando o mundo mais interconectado. Assim, implica um movimento de distanciamento da idéia sociológica clássica da sociedade como sistema bem delimitado e sua substituição por uma perspectiva que se concentra na forma como a vida social está ordenada ao longo do tempo e do espaço.
\end{abstract}

Neste sentido, a globalização proporciona uma redução no espaço e no tempo, vistos que as novas tecnologias de comunicação permitem uma maior interação entre os mercados, de forma instantânea e remota, podendo ser realizada uma operação financeira de qualquer local do planeta.

\title{
3 GLOBALIZAÇÃo E CRIMINALIDADE
}

Conforme leciona Alberto Silva Franco, com a intensificação da globalização, reduzindo distâncias e tempo de ação, a criminalidade se modificou, tornando-se uma criminalidade supranacional, apresentando uma estrutura organizada, caracterizandose em parte por uma desvinculação geográfica de um Estado, tornando mais difícil a determinação do local da prática delituosa, bem como a identificação de seus autores (FRANCO, 2000, p.120)

Assim, observa-se que a criminalidade no mundo globalizado é mais sofisticada, tendo uma estrutura organizada, hierarquizada, com especializações nos diversos campos de atuação. Analogia pode ser feita à estrutura de uma grande empresa, organizada em departamentos, com agentes especializados em cada atividade de que depende o funcionamento da mesma.

Temos aqui um aspecto negativo da globalização, qual seja, a internacionalização da criminalidade, com a qual o crime organizado, atuando nas 
mais diversas áreas, encontra campo fértil para a prática delituosa, dentre eles, o crime de lavagem de capitais.

Com a diminuição das barreiras impostas pelas fronteiras dos Estados propiciada pela globalização, e a velocidade dos meios de comunicação e transporte, as organizações criminosas passaram a planejar a atuação criminal de acordo com a benevolência e tolerância de cada Estado, utilizando-se dessa maneira do modelo transnacional para a prática delituosa.

Assim, com os problemas e poderes trazidos pela globalização, o direito penal e processual penal, com aquela velha noção de territorialidade e soberania, tem se mostrado ineficiente no combate à criminalidade transnacional.

Desta maneira, o Direito deve acompanhar as mudanças sociais, deve se adaptar às novas realidades para, eficientemente, possibilitar o combate ao crime, que, atualmente, alcança jurisdições e soberanias de diferentes Estados.

A soberania tradicional, estabelecida na Paz de Westfália (1948), que preceitua que os Estados soberanos não reconhecem nenhuma autoridade superior, deve se adaptar à nova realidade do mundo globalizado. A territorialidade tradicional torna-se incompatível com a criminalidade organizada transnacional, visto que, com a possibilidade de ação remota, através da internet, por exemplo, há uma incerteza quanto ao local do crime.

Com o surgimento de Organismos Internacionais, esses conceitos, soberania e territorialidade, não podem ser exercidos unicamente no interesse absoluto do Estado que o detém, devendo ser observados os interesses supranacionais.

O mundo tornou-se um campo fértil para o desenvolvimento da criminalidade organizada transnacional, desta maneira, os Estados precisam adaptar suas legislações a fim de tornar eficaz a persecução penal, tornando-a mais célere e mais abrangente, diminuindo a impunidade e a lucratividade que se tem com as práticas delituosas.

Os crimes praticados em jurisdições de diversos Estados tornam a ação menos visível, devendo os Estados estabelecer instrumentos mais céleres e menos burocráticos de cooperação internacional, propiciando maior eficiência à persecução penal, diminuindo, por consequente, a impunidade e lucratividade dos delitos. 
Com o advento da Constituição Federal de 1988, a cooperação internacional deixa de ser um compromisso moral e passa a ser uma obrigação jurídica, conforme preceitua o artigo 4ํㅡㄹ de nossa Carta Magna: "Art. 4 A República Federativa do Brasil rege-se nas suas relações internacionais pelos seguintes princípios: (...) IX cooperação entre os povos para o progresso da humanidade. [...]".

Assim, vislumbramos a importância da cooperação jurídica internacional para o enfrentamento da criminalidade globalizada, a qual propicia eficácia e eficiência à persecução penal, que, como esclarecido, transpõe as fronteiras dos Estados soberanos.

Sem essa atuação eficiente do direito penal no plano internacional, o mesmo cai em descrédito, razão pela qual é necessário estabelecer novas ferramentas para a persecução penal em escala mundial.

Vale ressaltar que a criminalidade organizada se desenvolve em diversas áreas, narcotráfico, terrorismo, tráfico de armas, tráfico de pessoas, corrupção, dentre outros, e, dentro de sua estrutura especializam as funções de cada agente. Com tal especialização, os avanços das técnicas nas práticas delituosas se intensificam, tornando-se mais eficazes, menos visíveis, e dificultando a atuação do Estado em combater a modalidade criminosa eleita.

Neste ponto, a lavagem de dinheiro se torna ferramenta de extrema importância para as organizações criminais, visto que, adotando tal procedimento, é possível trazer os lucros obtidos com o crime principal da organização para o mercado financeiro, dando ao capital auferido com o delito, aparência de licitude.

A globalização, no que tange ao aspecto econômico-financeiro, e os avanços tecnológicos, favorecem a expansão da prática de diversos crimes, dentre eles, o de lavagem de capitais, devendo os Estados, para coibir tal prática, adaptar suas legislações à realidade atual. 


\title{
4 FENÔMENO DA LAVAGEM DE CAPITAIS
}

\subsection{HISTÓRICO DA LAVAGEM DE CAPITAIS}

O termo lavagem de dinheiro foi utilizado pela primeira vez em um processo judicial no ano de 1982, o qual tratava de valores provenientes do crime de tráfico de drogas oriundas da Colômbia, entretanto, já era utilizado para descrever o método de ocultação de valores empregado pela máfia na década de 30. Naquela época, a máfia se utilizava de lavanderias para justificar a origem dos capitais ilícitos (BOTTINI, 2012).

O procedimento de lavagem de capitais, com a finalidade de dar aparência de licitude ao dinheiro obtido com o crime, não é criação recente, entretanto, seu combate é objeto do direito a poucas décadas.

Heba Shams descreve a evolução do combate à lavagem de dinheiro em três fases:

\begin{abstract}
a) Caráter meramente preventivo, regulatório, citando como exemplo os Estados Unidos, no qual autorizava o Secretário do Tesouro Americano a impor a obrigação de reportar operações financeiras às autoridades; b) Criminalização e Internacionalização, destacando a Convenção de Viena de 1988, a qual impunha aos países signatários a obrigação de criminalizar a lavagem de capitais; c)Supranacionalização, iniciada quando da criação do GAFI - Grupo de Ação Financeira Internacional (FATF - Finacial Action Task Force) em 1989, o qual tem como objetivo coordenar esforços internacionais para o combate à lavagem de dinheiro (SHAMS, 2004, p.2-4).
\end{abstract}

Analisando as fases do combate à lavagem de dinheiro, verificamos que, com o passar do tempo, essa prática delituosa foi ganhando importância, e, à luz do Princípio da ultima ratio, com a ineficiência de medidas administrativas para coibir tal fenômeno, não houve outra alternativa senão criminalizar tal conduta.

Cabendo ainda ressaltar que tratados internacionais trataram do tema lavagem de capitais, dentre eles, a Convenção de Viena de 1988 que impôs a obrigação aos Estados-membros da ONU de criminalizar a conduta delituosa em tela.

A criminalização em alguns países ocorreu antes mesmo da obrigação imposta pela Convenção de Viena de 1988, dos quais podemos citar: Itália em 1978, Alemanha em 1980 e EUA em 1986. 


\subsection{GERAÇÕES DE LEIS CRIMINAIS DE COMBATE À LAVAGEM DE DINHEIRO}

Inicialmente, conforme exposto acima, o combate à lavagem de dinheiro tinha caráter preventivo e regulatório, entretanto, com a intensificação de tal prática, foi necessária a criminalização da conduta de lavagem de capitais.

A legislação penal que criminaliza a lavagem de dinheiro evoluiu em etapas, as quais são denominadas pela doutrina de gerações, e são definidas de acordo com os crimes antecedentes geradores dos ativos ilícitos.

Três gerações são identificas e definidas pela doutrina. A primeira geração de leis considera o crime de lavagem de dinheiro somente aquele cuja ocultação e dissimulação do capital seja obtido com o tráfico ilícito de entorpecentes.

Vale dizer que o primeiro tratado internacional que impôs a obrigação de criminalizar a lavagem de dinheiro foi a Convenção das Nações Unidas contra o Tráfico llícito de Entorpecentes e Substâncias Psicotrópicas (Convenção de Viena de 1988), assim, as legislações, à época, tinham como crime antecedente somente o tráfico de drogas.

Pela eficiência do combate, por via reflexa, aos crimes antecedentes, iniciase uma nova etapa na legislação penal referente à lavagem de dinheiro. Surgem as leis de segunda geração, as quais ampliam o número dos crimes antecedentes, trazendo um rol taxativo de crimes. E aqui se insere a lei 9.613/98 que inaugurou 0 crime de lavagem de dinheiro na legislação pátria.

A terceira geração de leis extingue o rol taxativo de crimes antecedentes, considerando lavagem de dinheiro a ocultação ou dissimulação de valores advindos de qualquer infração penal, exatamente o que ocorreu em nosso ordenamento jurídico com a alteração promovida pela Lei 12.683/12.

\subsection{IMPORTÂNCIA DO COMBATE À LAVAGEM DE DINHEIRO NO PLANO INTERNACIONAL}

Com a globalização e as facilidades trazidas pelo desenvolvimento tecnológicos, o crime organizado viu a possibilidade de levar os ativos adquiridos com 
o crime para fora da jurisdição de seu país, introduzindo os mesmo em Estados cuja legislação favoreça a lavagem de capitais.

Historicamente, a doutrina atribui a lavagem de capitais, utilizando-se de mecanismos transnacionais, a Meyer Lansky, o qual teria se utilizado de bancos suíços para simular operações de empréstimos, a fim de dar aparência lícita a ativos derivados de crime. ${ }^{1}$

O combate à lavagem de capitais, no âmbito internacional, abrange diversas áreas do direito, podendo ser citados o Direito Penal, Processual Penal, Administrativo, Internacional, dentre tantos outros.

Desta maneira, a fim de se tornar eficiente a prevenção e persecução penal ao crime de lavagem de dinheiro, podemos destacar três ordens, quais sejam, penal, financeira e a cooperação internacional

No âmbito penal verifica-se a necessidade de se tipificar o delito e trazer instrumentos hábeis para o confisco dos bens decorrentes dos crimes praticados. $\mathrm{Na}$ ordem financeira, há a necessidade de se regular o setor, com a finalidade de se identificar operações financeiras que objetivam a lavagem de capitais. E, por fim, a cooperação internacional se presta a alcançar os ativos em outros países, sendo que o uso de tal ferramenta deve ser fomentado através de tratados e acordos internacionais.

Conforme ressalta Kai Ambos, a internacionalização do crime de lavagem de dinheiro torna seu combate de interesse transnacional (AMBOS, 2007, p.15), o que pode ser notado com os diversos tratados internacionais criados nas últimas décadas que dedicam dispositivos específicos ao enfrentamento de tal delito.

Tomando por base essa internacionalização do crime de lavagem de dinheiro, onde os atos são praticados em jurisdições de Estados diferentes atingindo a economia de diversos países, as ações destinadas ao seu combate não podem ser isoladas e internas, devendo haver grande integração entre os territórios envolvidos.

O dinheiro, objeto da lavagem de capitais, percorre países que não possuem legislação apropriada para seu combate, desta maneira, tendo-se em vista que o

\footnotetext{
${ }^{1}$ Lansky abriu uma conta em um banco suíço para garantir o proveito dos lucros obtidos com o crime de corrupção praticado pelo Governador da Louisiana, simulando um empréstimo financeiro.
} 
interesse é transnacional, faz-se necessária a imposição de sanções aos Estados coniventes ou negligentes.

Por todo o exposto, para o eficiente combate ao crime de lavagem de capitais, é inegável a importância da cooperação internacional entre os Estados, bem como a atuação conjunta destes, razão pela qual alguns Organismos Internacionais atuam nesse campo, a exemplo do GAFI - Grupo de Ação Financeira Internacional, ONU Organização das Nações Unidas, OCDE - Organização para a Cooperação e Desenvolvimento Econômico, Interpol, Banco Mundial, FMI - Fundo Monetário Internacional, dentre outros.

\section{A LAVAGEM DE DINHEIRO NO BRASIL}

O Brasil, na década de 90 , com a introdução do plano real, e, consequentemente, adquirindo certa estabilidade econômica, tornou-se seguro para investidores, sendo assim, atrativo para a prática de atos relacionados à lavagem de dinheiro.

Signatário da Convenção de Viena de 1988, a República Federativa do Brasil se obrigou a criminalizar a lavagem de dinheiro, entretanto, a lei que tipificou tal delito só foi publicada em 1998, qual seja, a lei 9.613/98.

Com o advento da lei, foi criado o COAF - Conselho de Controle das Atividades Financeiras, que tem como função regular e fiscalizar as atividades financeiras, com vistas a operações que possibilitem a ocultação de ativos de origem criminosa.

$\mathrm{Na}$ legislação pátria, foi adotado o termo lavagem de dinheiro, rechaçando o termo "branqueamento" de capitais adotado em alguns países da Europa. Esclarece o legislador no item 13 da Exposição de Motivos da Lei de Lavagem de Dinheiro que esta expressão, "[...] além de não estar inserida no contexto da linguagem formal ou coloquial em nosso País, sugere a inferência racista do vocábulo, motivando estéreis e inoportunas discussões" (BRASIL, 1996).

O crime de lavagem de dinheiro pode ser conceituado como sendo 0 ato ou sequência de atos praticados com a finalidade de encobrir a natureza, localização ou 
propriedade de bens, valores ou direitos de origem ilícita, para, no final, reintroduzi-lo à economia formal com aparência de lícito.

Ainda segundo o professor Renato Brasileiro (2004, p.282): Em síntese, a lavagem de capitais é o ato ou o conjunto de atos praticados por determinado agente com o objetivo de conferir aparência lícita a bens, direitos ou valores provenientes de uma infração penal.

O crime de lavagem de dinheiro foi inaugurado em nosso sistema jurídico pela Lei 9.613/98, a qual trouxe em seu artigo $1^{\circ} \mathrm{um}$ rol taxativo de crimes antecedentes, dos quais os valores ilícitos deveriam ser originados para a configuração do delito. Para a maioria da doutrina, em sua redação original, é uma espécie de legislação de segunda geração.

Com o advento da Lei 12.683/12, a qual extinguiu o rol taxativo de crimes antecedentes, passando a prever que o crime de lavagem de dinheiro estará configurado quando houver ocultação ou dissimulação de valores, bens ou direitos, provenientes, direta ou indiretamente, de infração penal. Com tal alteração, qualquer infração penal, seja crime ou contravenção, poderá ser antecedente do crime de lavagem de dinheiro. Desta maneira a legislação pátria passou a se enquadrar na terceira geração.

Quanto ao bem jurídico tutelado pelo crime de lavagem de dinheiro a doutrina é divergente. Entretanto, majoritariamente, entende-se que seria o sistema econômico-financeiro, visto que a lavagem de capitais traz como consequências o abuso do poder econômico, a concorrência desleal, o comprometimento do normal fluxo dos capitais, dentre outras relacionadas à segurança da ordem econômicofinanceira.

A lei de combate à lavagem de dinheiro traz em seu artigo $1^{\circ}$, caput, a tipificação de tal delito, senão vejamos: Art. 10 Ocultar ou dissimular a natureza, origem, localização, disposição, movimentação ou propriedade de bens, direitos ou valores provenientes, direta ou indiretamente, de infração penal. (Redação dada pela Lei no 12.683, de 2012) (BRASIL, 1998).

Temos dois núcleos no tipo penal, ocultar e dissimular, configurando condutas abrangidas pelos dispositivos, desde que os valores, objetos do crime, sejam 
provenientes de infração penal, conforme alteração legislativa promovida pela lei $12.683 / 12$.

Neste tópico, interessante ressaltar que 0 artigo $9^{\circ}$ da lei 9.613/98 elege determinadas pessoas, físicas e jurídicas, como garantidoras da lisura das operações financeiras, chamados de gatekeepers. Tais sujeitos estão obrigados a comunicar ao COAF qualquer atividade suspeita, sob pena de responsabilização.

\section{A LAVAGEM DE DINHEIRO SOB A ÓTICA INTERNACIONAL}

Com o progresso, intensificação e sofisticação do crime de lavagem de dinheiro, bem como a sua internacionalização, nasceu a necessidade de uma resposta internacional à criminalidade que se expandia. Assim, Estados e Organismos Internacionais passaram a criar instrumentos para o combate à lavagem de dinheiro.

Diante da preocupação global com a expansão do crime de lavagem de capitais, diversos acordos e tratados internacionais, que traziam instrumentos de combate a tal delito, foram celebrados.

Além dos tratados internacionais, os quais possuem uma celebração mais burocrática e morosa, o soft law2 ${ }^{2}$ foi utilizado entre os Estados para o combate eficaz do crime de lavagem de dinheiro, visto que são mais céleres e capazes de acompanhar o progresso tecnológico dos modelos de lavagem de capitais.

A ONU, por ser o órgão internacional de maior expressão neste âmbito, visto que abrange um grande número de Estados-membros, possui destaque no combate à lavagem de capitais, pois os tratados celebrados no âmbito desta organização são ratificados por um grande número de países. Dentre os mais importantes, podemos citar as Convenções de Viena de 1988, Palermo e Mérida, as quais trazem em seu bojo instrumentos de combate à lavagem de dinheiro e cooperação internacional.

Tamanha é a importância dada ao combate à lavagem de dinheiro pela ONU, que foi instituída uma rede de informações no combate à lavagem de dinheiro em 1998 (International Money Laundering Information Network).

\footnotetext{
${ }^{2}$ Soft law se refere a instrumento celebrados entre Estados e atores não estatais, entretanto, não geram obrigações jurídicas, mas orientam a conduta das partes.
} 


\subsection{CONVENÇÃO DE VIENA DE 1988}

A Convenção das Nações Unidas Contra o Tráfico llícito de Entorpecentes e Substâncias Psicotrópicas traz a previsão da lavagem de dinheiro em seu corpo, em que pese tenha como finalidade precípua o combate ao narcotráfico.

Esta convenção, internalizada através do Decreto n. 154, de 26-6-1991, em seu artigo 3ำ 1, b, além de estabelecer a obrigação dos Estados-partes criminalizar a lavagem de dinheiro, traçou o esboço do crime de lavagem de capitais, tornando-a o instrumento de maior importância no combate a tal delito, senão vejamos:

1 - Cada uma das Partes adotará as medidas necessárias para caracterizar como delitos penais em seu direito interno, quando cometidos internacionalmente: (...) b) i) a conversão ou a transferência de bens, com conhecimento de que tais bens são procedentes de algum ou alguns dos delitos estabelecidos no inciso a) deste parágrafo, ou da prática do delito ou delitos em questão, com o objetivo de ocultar ou encobrir a origem ilícita dos bens, ou de ajudar a qualquer pessoa que participe na prática do delito ou delitos em questão, para fugir das conseqüências jurídicas de seus atos; ii) a ocultação ou o encobrimento, da natureza, origem, localização, destino, movimentação ou propriedade verdadeira dos bens, sabendo que procedem de algum ou alguns dos delitos mencionados no inciso a) deste parágrafo ou de participação no delito ou delitos em questão.

A obrigação imposta de criminalizar a lavagem de dinheiro pela Convenção de Viena de 1988, objetiva atingir, de forma indireta, o crime de tráfico ilícito de entorpecentes, descapitalizando as organizações criminosas. Desta maneira, atacase $o$ aspecto financeiro do produto do narcotráfico, desestimulando sua atividade.

Dentre os principais aspectos tratados pela convenção em estudo a respeito do crime de lavagem de dinheiro, podemos citar algumas imposições de adaptação da legislação interna dos Estados-parte:

a) obrigação de criminalizar a lavagem de ativos decorrentes do narcotráfico;

b) cooperação internacional para facilitar as investigações;

c) facilitar a extradição em relação à lavagem de dinheiro;

d) facilitar o confisco dos bens dos narcotraficantes;

e) sigilo bancário não pode servir de escudo à investigação em âmbito judicial.

A nossa legislação de combate à lavagem de capitais tomou por base a linha traçada pela Convenção de Viena de 1988 , criminalizando tal conduta no artigo $1^{\circ}$ da 
lei 9.613/98, entretanto, já em sua origem trouxe um rol taxativo de crimes antecedentes, não se limitando ao narcotráfico, enquadrando-se assim, desde o nascedouro, em uma legislação de segunda geração.

\subsection{CONVENÇÃO DE PALERMO}

A Convenção das Nações Unidas Contra o Crime Organizado Transnacional, de 15 de novembro de 2000 , foi incorporada ao ordenamento jurídico nacional através do Decreto 5.015, em 15 de março de 2004.

Em seu texto este tratado estipula a ampliação do rol dos crimes antecedentes da lavagem de dinheiro, objetivando, principalmente, alcançar aqueles praticados pelas organizações criminosas.

Desta maneira, a Convenção de Palermo pode ser considerada uma evolução em relação à Convenção de Viena de 1988, visto que estabelece diversos crimes cujo produto pode ser considerado passível de lavagem de dinheiro.

O tratado ora estudado vai além, prevê medidas de regulação e controle das instituições financeiras, com o objetivo de identificar operações que possam configurar lavagem de capitais, instituindo o conceito do know your costumer (conheça seu cliente) e o gatekeepers (garantidores da licitude das operações), os quais se encontram presentes no artigo 9을 Lei de Lavagem de Dinheiro.

Nesta convenção os artigos 6 e 7 são dedicados à lavagem de dinheiro, aquele criminalizando a lavagem e este trazendo medidas de prevenção. Dentre as inovações trazidas na Convenção de Palermo, citamos:

a) cooperação e intercambio internacional de informações;

b) detecção e monitoramento de operações financeiras transnacionais;

c) aperfeiçoamento da cooperação internacional;

d) controle das movimentações de valores por parte das instituições financeiras;

Pelo exposto, notamos que a Convenção de Palermo é o marco inicial da segunda e terceira geração de legislação de combate à lavagem de dinheiro sob a ótica internacional. 
A Convenção, em seu item 13, descreve de forma minuciosa a cooperação internacional para fins de confisco. Inova em promover a transmissão espontânea de informações, o que faz no item 18.4 .

\subsection{CONVENÇÃO DE MÉRIDA}

A preocupação internacional com a corrupção se deve ao fato de que o criminoso se infiltra na estrutura do Estado, e como um parasita, retira deste, parte de seus recursos, trazendo danos ao desenvolvimento social do país e a sua economia.

Neste diapasão, a Assembleia Geral da ONU no ano de 2000, através da Resolução 55/61, declarou a necessidade de criar instrumentos jurídicos internacionais que promovam o combate à corrupção.

A Convenção das Nações Unidas Contra a Corrupção, de 09 de dezembro de 2003, foi internalizada pelo Decreto 5.687, de 31 de janeiro de 2006, trazendo em seu artigo 14 diversos instrumentos de combate à lavagem de dinheiro, impondo ao Estado-parte a necessidade de tornar mais rigoroso o controle administrativo sobre os setores que frequentemente são utilizados na lavagem de capitais, bem como medidas de fomento à cooperação internacional. Dentre tais imposições encontramos:

a) maior rigor na supervisão das instituições financeiras;

b) cooperação entre as autoridades nacionais e internacionais relacionadas ao combate de lavagem de capitais;

c) controle da movimentação financeira transnacional;

d) instrumentos de cooperação internacional, dentre eles: extradição, translado de pessoas condenadas a cumprir pena, assistência jurídica recíproca, investigação conjunta, bem como técnicas especiais de investigação (entrega vigiada, vigilância eletrônica e operações secretas);

e) obrigação dos Estados-partes em criminalizar a lavagem de capitais e a imposição de adoção da gama mais ampla possível de crimes determinantes;

f) recuperação de ativos, devendo ser objeto de cooperação internacional. 
$\mathrm{Na}$ legislação interna de combate à lavagem de dinheiro, podemos observar o cumprimento do que foi imposto na Convenção através da inovação legislativa trazida pela lei 12.683/12.

Citamos a ampliação dos crimes antecedentes de forma ampla, passando a ser uma legislação de terceira geração.

O aprimoramento de medidas assecuratórias como as medidas cautelares patrimoniais, relacionadas à recuperação dos ativos, bem como a possibilidade de tais medidas recaírem, além do produto da lavagem, como era texto original da lei 9.613/98, sobre instrumentos do crime e produtos da infração antecedente.

Ainda no aspecto da recuperação de ativos, a inovação legislativa possibilitou a alienação antecipada, a fim de se preservar o valor do bem ou quando este é de difícil manutenção.

A lei 12.683/12, sob a égide da Convenção de Mérida trouxe a ampliação das pessoas físicas e jurídicas responsáveis, os gatekeepers, pela comunicação das operações suspeitas.

\section{CONCLUSÃO}

Por todo o exposto no presente trabalho, é possível concluir que com a globalização, os avanços tecnológicos nos meios de comunicação e transporte, a criminalidade se adaptou, expandiu seu campo de atuação para além-fronteiras, se internacionalizando.

A lavagem de dinheiro evoluiu, criando novos modelos, menos visíveis e mais intensos, propiciando mais segurança nas operações clandestinas que trazem aparência de licitude aos capitais advindos do submundo da criminalidade.

Os conceitos tradicionais de territorialidade e soberania não são mais suficientes para combater a nova ordem criminal que se instalou com o advento da globalização, a qual tornou mais tênue as barreiras impostas pelas fronteiras dos Estados.

Por estas razões, o interesse no combate à lavagem de dinheiro deixou de ser interno, passando a ser transnacional, chamando a atenção de organismo 
internacionais. Assim, diversos tratados foram firmados a fim de combater a lavagem de ativos.

Os tratados estudados no presente artigo, quais sejam, Convenção de Viena de 1988, Convenção de Palermo e Convenção de Mérida, impuseram aos Estadospartes a obrigação de adaptarem suas legislações internas de persecução penal aos novos mecanismos utilizados pela criminalidade. $E$ foi além, trouxe instrumentos de cooperação internacional que propiciam uma maior eficiência no combate a tais delitos que, na atualidade, percorrem jurisdições de diversos territórios.

Ressalte-se que os organismos internacionais que atuam no combate à lavagem de dinheiro estão sempre atentos às mudanças dos modelos utilizados pela criminalidade, desta maneira podem coordenar e orientar os Estados e Órgão Internacionais a modificarem seus procedimentos e legislações, a fim de prevenir e combater a criminalidade transnacional.

A identificação dos processos de lavagem de dinheiro, objetivando a desestruturação dos modelos de lavagem de dinheiro, promove não só o combate ao delito em comento, mas também ao delito antecedente.

Por fim, concluímos pela extrema necessidade de uma interação e cooperação entre os Estados, a fim de combater a lavagem de capitais, visto que, com a maior eficiência das normas de combate a tal delito e o sucesso da recuperação dos ativos, promove-se a descapitalização das organizações criminosas, enfraquecendoas, tornando menos atrativa a prática de tal modalidade criminosa.

\section{REFERÊNCIAS}

ADOLFO, Luiz Gonzaga Silva. Globalização e Estado Contemporâneo. São Paulo: Memória Jurídica, 2001.

AMBOS, Kai. Lavagem de dinheiro e direito penal. Porto Alegre: Sérgio Antônio Fabris, 2007.

ANSELMO, Márcio Adriano. Lavagem de dinheiro e cooperação jurídica internacional. São Paulo: Saraiva, 2013.

BOTTINI, Pierpaolo Cruz. Nova Lei de Lavagem trará problemas à Justiça. Revista Consultor Jurídico, São Paulo, 09 jul 2012. Disponível em: 
https://www.conjur.com.br/2012-jul-09/direito-defesa-lei-lavagem-dinheiro-traraproblemas-justica. Acesso em 06 jun 2018.

BRAGA, Juliana Toralles dos Santos. Lavagem de dinheiro - Origem histórica, conceito e fases. In: Âmbito Jurídico, Rio Grande, XIII, n. 80, set 2010. Disponível em:

$<$ http://www.ambitojuridico.com.br/site/index.php?n link=revista artigos leitura\&artig o id=8425>. Acesso em 06 jun 2018.

BRASIL. Ministério da Justiça. Exposição de Motivos n. 692/MJ, de 18 de dezembro de 1996. Submetemos à apreciação do Presidente da República projeto de lei que criminaliza a lavagem de dinheiro e a ocultação de bens, direitos ou valores que sejam oriundos de determinados crimes de especial gravidade. Disponível em: http://coaf.fazenda.gov.br/menu/legislacao-e-normas/legislacao1/Exposicao\%20de\%20Motivos\%20Lei\%209613.pdf. Acesso em: 06 jun. 2018.

Lei no 9.613, de 3 de março de 1998. Disponível em: http://www.planalto.gov.br/ccivil 03/LEIS/L9613.htm. Acesso em: 06 jun. 2018.

DALMAS, Samir Bahlis. Globalização e criminalidade organizada. Conteúdo Jurídico, Brasília-DF: 02 ago. 2014. Disponível em: <http://www.conteudojuridico.com.br/?artigos\&ver=2.49231\&seo=1>. Acesso em: 06 jun. 2018

FRANCO, Alberto Silva. Globalização e Criminalidade dos Poderosos. Revista Brasileira de Ciências Criminais, São Paulo, v. 8, n. 31, jul./set. 2000.

LIMA, Renato Brasileiro de. Legislação criminal especial comentada. Salvador: Jus Podivm, 2014.

SILVEIRA, Vladmir Oliveira. Direitos Humanos Fundamentais das Pessoas com Deficiência. Revista Direito UFMS, Campo Grande, MS- Edição Especial- p. 103-130 - jan/jun. 2015.

SILVEIRA, Vladmir Oliveira; CONTIPELLI, Ernani. Direitos Humanos Econômicos na perspectiva da Solidariedade: desenvolvimento integral. In: XVI Encontro Nacional CONPEDI, 2008, Salvador - BA. Anais XVI Encontro Nacional do CONPEDI, 2008.

SHAMS, Heba. Legal Globalization: Money Laundering Law and Other Cases. London: British Institute of International and Comparative Law, 2004, p. 2-4. In: ANSELMO, Márcio Adriano. Lavagem de dinheiro e cooperação jurídica internacional. São Paulo: Saraiva, 2013. 